DOI: $10.4274 /$ tpa.45.264

\title{
Türkiye’de illerde bebek ölüm hızı ne kadar doğru hesaplanabiliyor? Bursa'dan bir çalışma
}

\author{
How correct are the infant mortality rate calculations in the provinces of Turkey? A study from Bursa
}

\author{
Kayıhan Pala, Alpaslan Türkkan, Harika Gerçek \\ Uludağ Üniversitesi Tıp Fakültesi, Halk Sağı̆ğı Anabilim Dalı, Bursa, Türkive
}

\section{Özet}

Amaç: Bursa'da bebek ölüm hızı il Sağlık Müdürlüğü tarafından 2008 yılı için binde 6,0 olarak açıklanmaktadır. Türkiye’ye göre çok düşük olan bu göstergeyi değerlendirmek amacıyla bir araştırma yapılmasına gerek duyulmuştur. Bu araştırmanın amacı, Bursa'da 2008 yılındaki bebek ölüm hızının tahmin edilmesidir.

Gereç ve Yöntem: Bebek ölüm hızının hesaplanması için İı Sağlık Müdürlüğü’nden, Türkiye İstatistik Kurumu'ndan ve İ Nüfus ve Vatandaşlık Müdürlüğü'nden veri istenmiştir. Ayrıca Bursa sınırları içerisinde bulunan bütün belediyelerden veri toplanmıştır.

Bulgular: Bursa'da 2008 yılında İ Sağlık Müdürlüğü'nün verilerine göre 206, ilı Nüfus ve Vatandaşlık Müdürlüğü’nün verilerine göre 235 ve Belediyelerden toplanan verilere göre 795 bebek yaşamını yitirmiştir. Bu çalışmada, bebek ölüm hızı binde 20,8 olarak tahmin edilmiştir.

Çıkarımlar: Bebek ölüm hızı Bursa III Sağlık Müdürlüğü tarafından duyurulan değerden çok daha yüksek bulunmuştur. Sağlık göstergelerini sağlık sisteminin başarısını değerlendirmek için kullanırken, ilk dikkat edilmesi gereken nokta doğru hesaplamak olmalıdır. Bebek ölüm hızının hesaplanması sırasında mezarlık kayıtlarının da kullanılması için bir düzenlemenin yapılması uygun olabilir. (Türk Ped Arş 2010; 45: 264-7)

Anahtar sözcükler: Bebek ölüm hızı, Bursa, sağlık göstergeleri, sağlık kayıtları

\section{Summary}

Aim: The Provincial Health Authority, declared that in 2008, infant mortality rate was 6,0 per thousand, in Bursa. As this rate is very low for Turkey, there was a need to investigate it. The objective of this study was to estimate the infant mortality rate for 2008 , in Bursa.

Material and Method: In order to calculate the infant mortality rate, data was requested from the Provincial Health Authority, Turkish Statistical Institute and the Provincial Population and Citizenship Authority. We also gathered data from every municipality in Bursa.

Results: There were 206 and 235 infant deaths according to the Health Authority and the Population and Citizenship Authority respectively. According to data from the municipalities the number of infant deaths was 795 . We estimated the infant mortality rate as 20,8 per thousand. Conclusions: We found a much higher infant mortality rate than the Health Authority of Bursa. When using health indicators to evaluate the achievements of the health system the most important point is to collect reliable data. It might be appropriate also to use cemetery records while calculating the infant mortality rate. (Turk Arch Ped 2010; 45: 264-7)

Key words: Bursa, health indicators, health records, infant mortality rate

\section{Giriş}

Sağlık sistemlerinin başarısı, sağlık sistemi göstergeleri (hız, orantı ya da sayılar) ile ölçülür. Bunlar, hizmetin var oluşunu, halk tarafından kullanılma oranını, halkın hizmetleri benimsemesini, niteliğini, sürekliliğini, maliyetini ve verimliliğini gösteren ölçütlerdir (1). Sağlık göstergeleri içerisinde en önemlilerinden birisi bebek ölüm hızıdır (BÖH).
Son yıllarda sağlık sistemlerinin başarısı BÖH, beş yaşın altındaki çocuk ölüm hızı, anne ölüm hızı ve erişkin ölüm hızı gibi bilinen göstergeler yerine; sakatlığa uyarlanmış yaşam beklentisi (Disability adjusted life expectancy, DALE), sakatlığa uyarlanmış yaşam yılları (Disability adjusted life years, DALY's) ve sağlıklı yaşam beklentisi (Healthy life expectancy, HALE) gibi "yeni” göstergelerle değerlendirilmek istenmektedir (2). Ancak özellikle kaynakları sınırlı olan ülkeler için toplumun sağlığının değer- 
lendirilmesinde kolay hesaplanabilen bir gösterge olarak BÖH önemini korumaktadır (3).

Türkiye'de Sağlık Bakanlığı da sağlık sisteminin durumunu yansıtabilecek temel sağlık göstergelerinin başıcaları arasında ilk sırada BÖH'ü saymaktadır (4).

Türkiye Nüfus ve Sağılı Araştırması (TNSA) sonuçlarına göre, Türkiye'de BÖH, 2003-2008 yılları arasındaki beş yıllık dönem için binde 17,6; 1998-2003 yılları arasındaki beş yıllık dönemde ise binde 28,7 olarak tahmin edilmiştir. Buna göre BÖH, 1998-2003 ile 2003-2008 yılları arasındaki beş yıllık dönemde yüzde 47 azalmıştır (5).

Bursa'da ise BÖH II Sağlık Müdürlüğü tarafından 2006 yılında binde 7,4, 2007 yllında binde 6,8 ve 2008 yılı için binde 6,0 olarak açıklanmaktadır (6). Türkiye'ye göre çok düşük olan bu göstergeyi değerlendirmek amacıyla II Sağlık Müdürlüğü tarafından düzenlenen basın toplantısında, Sağlık Bakanlığı'nın ana ve çocuk sağlığı konusundaki tasarılarının başarıyla sürdürülmesi sonucunda Bursa'daki BÖH'ün gelişmiş ülkeler düzeyine indiği açıklanmaktadir (7).

İ Sağlık Müdürlüğü tarafından açıklanan BÖH'ün gerçekten iddia edildiği gibi sağlık hizmetlerinin başarılya sürdürülmesi sonucunda mı; yoksa yanlış tahmin edilmesinden kaynaklanan bir hatayla mı böyle düşük bulunduğunun anlaşıması amacıyla bir araştırma yapılmasına gerek duyulmuştur.

Bu araşıırmanın amacı, Bursa'da 2008 yılındaki bebek ölüm hızının tahmin edilmesidir.

\section{Gereç ve Yöntem}

Bebek ölüm hızı; bir takvim yılında, bir yaşın altında gerçekleşen ölümlerin aynı yıl içerisindeki canlı doğum sayısına bölünmesiyle bulunmaktadır (8). Hızın hesaplanması için iki veriye gereksinim duyulmaktadır: bebek ölümü sayısı ve canlı doğum sayısı.

2008 yılı içerisinde ölen bebeklerin sayısını elde etmek amacıyla İ Sağlık Müdürlüğü'nden, Türkiye İstatistik Kurumu'ndan (TÜIKK) ve İ Nüfus ve Vatandaşlık Müdürlüğü'nden veri istenmiş̧ir. Ayrıca Bursa sınırları içerisinde bulunan Büyükşehir Belediyesi de içinde olmak üzere bütün belediyelerden veri toplanmıştır. İ Sağlık Müdürlüğü sağlık ocaklarından sağlık grup başkanlıkları yoluyla Müdürlüğe gönderilen verileri resmi bir yazı ile iletmiştir (9). Türkiye İstatistik Kurumu 2008 yılı için elinde ölüm verisi olmadığını bildirmiştir. İı Nüfus ve Vatandaşlık Müdürlüğü ilçelere göre bebek ölümü sayısını resmi bir yazı ile iletmiştir (10).

Bursa'da 2008 yilında on yedi ilçe bulunmaktadır. Bunlardan üçü Büyükşehir Belediyesi sınıları içinde olduğu için, ölüm kayıtları Büyükşehir Belediyesi tarafından tutulmaktadır. Araştırmacılar tarafından Büyükşehir Belediyesi ve 14 ilçe belediyesinin defin ruhsatı veren birimleri ziyaret edilerek 2008 yılında yaşamlarını yitiren bebeklerin sayısı ve çeşitli özellikleri (ad, soyad, ölüm tarihi vb.) istenmiştir. Belediyelerden alınan veriler ölü doğumları içermemektedir.

2008 yılı içerisinde canlı doğan bebeklerin sayısını elde etmek amacıyla III Sağlık Müdürlüğü'nden, İ Nüfus ve Vatandaşlık Müdürlüğü'nden ve TÜIK'den veri istenmiştir. II Sağlık Müdürlüğü sağlık ocaklarından sağlık grup başkanlıkları yoluyla Müdürlüğe gönderilen verileri resmi bir yazı ile iletmiştir (9). II Nüfus ve Vatandaşlık Müdürlüğü canlı doğum sayısını resmi bir yazı ile iletmiştir (10). Türkiye İstatistik Kurumu'ndan 31 Aralık 2008 tarihi itibariyle Bursa'da adrese dayalı nüfus kayıt sistemi 2008 yılı nüfus sayımı sonuçlarına göre sıfır yaşındaki bebeklerin sayısı ise satın alma yoluyla edinilmiştir.

\section{Çalıșmanın sınırlıııları}

1. Kırsal alanda meydana gelen bebek ölümlerine ilişkin veri toplanamamıştır. Bursa'da toplumun yaklaşık beşte birinin kırsal alanda yaşadığı göz önüne alııırsa, bu durum BÖH'ün daha düşük tahmin edilmesine yol açabilir.

2. Büyükşehir Belediyesi dışındaki belediyelerden alınan kimi veriler eksiktir. Örneğin her bebeğin adı ve soya$\mathrm{d}$, anne-babasının kimlik bilgileri alınamamıştır. Bu nedenle öldüklerinde adları olmayan bebeklerin sayısı Büyükşehir Belediyesi'nden alınan veriyle sınırlı kalmıştır.

3. İ Nüfus ve Vatandaşlık Müdürlüğü'nden canlı doğum sayısı alınmakla birlikte, alınan veri ile ilgili bazı sıkıntılar olabileceği için BÖH tahmin edilirken TÜíK verisi kullanılmıştır. Bunlar (görevlilerden öğrenildiği kadarıyla) başka illerde gerçekleşen doğumların Bursa'da kayıt altına alınması ve geçmiş yıllarda doğan bebeklerin kayıtlarının 2008 yılında yapılıma olasılığı gibi sıkıntılardır. Türkiye İstatistik Kurumu verisi de yıl sonu itibarıyla Bursa il sınırları içerisinde yaşayan bebekleri göstermesi bakımından sınırlılık içermekle birlikte, İl Nüfus ve Vatandaşlık Müdürlüğü'nün verisine tercih edilmiştir. Hızın hesaplanmasında kullanılan sayı bu nedenle canlı doğum sayısı değil, TÜiK tarafından verilen sıfır yaşındaki nüfustur. Bebek ölüm hızı tahmin edilirken, sıfır yaşındaki nüfusa ölen bebeklerin sayısı eklenmiştir.

\section{Bulgular}

Bursa'da 2008 yılında İ Sağlık Müdürlüğü'nün verilerine göre 206, III Nüfus ve Vatandaşlık Müdürlüğü'nün verilerine göre ise 235 bebek yaşamını yitirmiştir. Belediyelerden alınan bebek ölümü sayısı ise her iki kurumun verisinden de yüksektir. Belediyelerden toplanan verilere göre aynı yıl içinde ölen bebek sayısı 795'tir (Tablo 1). Ölüm verileri bir ilçe dışında (Büyükorhan) kurumlar arasında farklılık göstermektedir.

Büyükşehir Belediyesi ölüm kayıtlarında yer alan 686 bebekten 517 'sinin $(\% 75,4)$ öldükleri sırada adlarının olmadığı anlaşılmıştır. Bu bebekler ölüm kayıtlarında soyadları ile yer almaktadırlar. 
II Sağlık Müdürlüğü'nün verilerine göre Bursa'da 2008 yılında canlı doğan bebek sayısı 34 362'dir. İı Nüfus ve Vatandaşlık Müdürlüğü'nden alınan veriye göre 2008 yılı içerisinde gerçekleşen doğum sayısı 42 052'dir. Türkiye İstatistik Kurumu'ndan alınan 31 Aralık 2008 tarihi itibariyle Bursa'da adrese dayalı nüfus kayıt sistemi 2008 yılı nüfus sayımı sonuçlarına göre sıfır yaşındaki bebeklerin sayısı 37423 'tür. Bursa'da 2008 yılı için değişik kurumlardan elde edilen veriler kullanılarak hesaplanan BÖH binde 5,6 ile 20,8 arasında değişmektedir (Tablo 2). Bu çalışmada, bebek ölüm hızı binde 20,8 olarak tahmin edilmiştir.

Tablo 1. Bursa'da gerçekleşen bir yaşın altındaki ölümler (2008)

\begin{tabular}{|l|c|c|c|}
\hline \multirow{2}{*}{ İçe } & \multicolumn{3}{|c|}{ Veri kaynağına göre bebek ölümleri (2008) } \\
\cline { 2 - 4 } & $\begin{array}{c}\text { i } \\
\text { Sağlık } \\
\text { Müdürlüğü }\end{array}$ & $\begin{array}{c}\text { il Nüfus ve } \\
\text { Vatandaşlık } \\
\text { Müdürlüğü }\end{array}$ & Belediyeler \\
\hline Büyükşehir* & 115 & 197 & 686 \\
\hline Kestel & 7 & 0 & 12 \\
\hline Gürsu & 13 & 2 & 14 \\
\hline İnegöl & 28 & 12 & 12 \\
\hline Orhaneli & 6 & 0 & 1 \\
\hline Harmancık & 0 & 0 & 1 \\
\hline Büyükorhan & 0 & 0 & 0 \\
\hline Keles & 4 & 2 & 2 \\
\hline Yenişehir & 5 & 5 & 10 \\
\hline İznik & 0 & 1 & 1 \\
\hline Orhangazi & 2 & 1 & 17 \\
\hline Gemlik & 5 & 2 & 18 \\
\hline Mudanya & 4 & 0 & 3 \\
\hline Karacabey & 7 & 5 & 7 \\
\hline Mkemalpaşa & 10 & 8 & 11 \\
\hline Toplam & 206 & 235 & 795 \\
\hline
\end{tabular}

* Yıldırm, Osmangazi ve Nilüfer

\begin{tabular}{|l|c|c|c|}
\hline \multicolumn{3}{|c|}{$\begin{array}{c}\text { Tablo 2. Bursa'da } 2008 \text { yılı için bebek ölüm hızının tahmin } \\
\text { edilmesi }\end{array}$} \\
\hline Veri kaynağı & $\begin{array}{c}\text { Ölen } \\
\text { bebek } \\
\text { sayısı }\end{array}$ & $\begin{array}{c}\text { Canlı } \\
\text { doğum } \\
\text { sayısı }\end{array}$ & $\begin{array}{c}\text { Bebek } \\
\text { ölüm hızı } \\
\text { (Binde) }\end{array}$ \\
\hline II Sağlık Müdürlüğü & 206 & 34362 & 6,0 \\
\hline II Nüfus ve Vatandaşlık Müdürlüğü & 235 & 42052 & 5,6 \\
\hline Türkiye İstatistik Kurumu & -- & 37423 & -- \\
\hline Belediyeler & 795 & -- & -- \\
\hline $\begin{array}{l}\text { Belediyeler+ İ Nüfus ve } \\
\text { Vatandaşlık Müdürlüğü }\end{array}$ & 795 & 42052 & 18,9 \\
\hline $\begin{array}{l}\text { Türkiye İstatistik Kurumu } \\
\text { +Belediyeler }\end{array}$ & 795 & $37423^{\star}$ & $20,8^{* *}$ \\
\hline
\end{tabular}

* Türkiye İstatistik Kurumu verisi canlı doğum sayısı değil, sıfır yașındaki nüfustur **Bebek ölüm hızı hesaplanırken, canlı doğum sayısı, sıfır yașındaki nüfusa ölen bebek sayısı (37 423+795) eklenerek 38218 olarak kabul edilmiştir

\section{Tartışma}

Bu çalışmada BÖH binde 20,8 ile Bursa III Sağlık Müdürlüğü tarafından duyurulan değerden (binde 6,0) çok daha yüksek bulunmuştur. Bunun temel nedeni Bursa'da gerçekleşen bebek ölümlerinin büyük bir bölümünün İI Sağlık Müdürlüğü'nün kayıtlarında yer almaması olabilir. Ülkemizde halen yürürlükte olan 224 sayılı yasa gereği sağlık ocaklarının kendi sorumluluk alanı içinde meydana gelen ölüm ve doğumları her ay düzenli bir şekilde tespit ederek II Sağlık Müdürlüklerine bildirmeleri gerekir. Ancak bu durum çalışan eksikliği, konuya karşı ilgi azlığı yanında yöneticide denetim ve değerlendirme olgusunun yeterince olmaması yüzünden aksamaktadır. Sonuç olarak sağlıklı ve güvenilir BÖH'ler hesap edilememektedir (11). Ancak, Sağıık Bakanlığı tarafından, bir milletvekilinin sormaSı üzerine yanıtlanan bir soru önergesinde 2008 yılında Bursa'da 657 bebek ölümünün bildirildiğinin açıklanması kafa karıştırmaktadır (12). Çünkü kuramsal olarak Sağlık Bakanlığı'nın açıkladığı verinin İ Sağlık Müdürlüğü tarafından gönderilen veri olması beklenir. Oysa Bakanlık tarafından açıklanan bebek ölümü sayısı Müdürlüğün bildirdiği sayıdan 451 bebek daha fazladır. Bu durumda ortaya iki olasılık çıkmaktadır: ya Bakanlık farklı bir veri kaynağı kullanmaktadır, ya da İ Sağlık Müdürlüğü Bakanlığa bildirdiği bebek ölümlerini BÖH'ü hesaplarken kullanmamaktadır. Her iki olasııı da kamu sağılık yönetimi açısından düşündürücüdür ve irdelenmelidir.

Türkiye'de genel olarak ölümlerin kayıt altına alınmasında ve ölümlerle ilgili hızların hesaplanmasında bir sorun yaşanmaktadır. İzmir'de Narlıdere Eğitim ve Araştırma Sağlık Bölgesi'nde de 1999 yılına iliş̧in BÖH binde 13,1 olarak hesaplanmış; daha sonra yapılan bir araştırma ile yedi bebek ölümünün kayıtlara geçmediği saptanmış ve BÖH binde 17,6 olarak düzeltilmiştir (13).

Bursa II Sağlık Müdürlüğü tarafından açıklanan BÖH değerinin gerçeğin çok altında olması, yalnızca 2008 yılına özgü bir durum da değildir. Müdürlük 2000 yılına ilişkin BÖH'ü binde 16,6 olarak duyururken (6); Devlet İstatistik Enstitüsü genel nüfus sayımı sonuçlarına göre Bursa'da BÖH'ü aynı yıl için binde 39 olarak açıklamaktadır (14). Dolayısıyla yıllar içinde yinelenen bir hatadan söz etmek olanaklıdır.

Türkiye'de yapılan çeşitli araştırmalar kentlerde mezarlık kayıtlarının güvenilir bir veri kaynağı olduğunu ve Devlet İstatistik Enstitüsü formlarından elde edilemeyen bilgileri de içerdiğini ortaya koymaktadır. Örneğin 1987 yılında İstanbul'da gerçekleştirilen bir araştırmada mezarlık verilerine göre toplam ölümlerin sayısı, Devlet İstatistik Enstitüsünün gösterdiği sayıdan daha yüksek bulunmuştur (15). Bu nedenle BÖH'ün hesaplanması sırasında be- 
lediyelerden elde edilecek defin ruhsatı kayıtlarının kullanılması uygun olabilir. Çünkü yaşamını yitiren bebeklerin büyük bir çoğunluğunun henüz nüfus cüzdanı çıkarımadan öldükleri anlaşılmaktadır. Bizim araştırmamızda Bursa Büyükşehir Belediyesi defin ruhsatı kayıtlarına göre ölen her dört bebekten üçünün henüz adları bile konulmadığı, dolayısıyla nüfus cüzdanlarının olmadığı bulunmuştur. Bu durumda III Nüfus ve Vatandaşlık Müdürlüğü verilerine dayanarak $\mathrm{BÖH}$ hesaplamak doğru olmayacaktır.

\section{Sonuç ve öneriler}

Bu çalışmada Bursa'daki BÖH İ Sağlık Müdürlüğü'nün açıkladığı değerden çok daha yüksek bulunmuştur. Üstelik bulunan değer, bırakınız gelişmiş ülkelerin düzeyine inmeyi; Türkiye için TNSA tarafından açıklanan değerden bile yüksektir.

Bursa'da eksik veriler yüzünden yanlış hesaplanan BÖH, ildeki sağlık hizmetlerinin doğru değerlendirilememesine yol açmaktadır. Bebek ölüm hızını sağlık sisteminin başarısını değerlendirmek için kullanırken, ilk dikkat edilmesi gereken nokta doğru hesaplamak olmalıdır. Türkiye'de illerde BÖH'ün doğru hesaplanamamasına ilișkin sorunların irdelenmesi ve ivedilikle giderilmesi gerekmektedir. Bebek ölüm hızının hesaplanması sırasında mezarlık kayıtlarının da kullanılması için bir düzenlemenin yapılması uygun olabilir.

\section{Teşekkür}

Bu çalışma sırasında ilçe belediyelerine giderek veri toplayan Dr. Mehmet Gülay, Dr. Özlem Kizek Özçay ve Dr. Pelin Emiroğlu'na teşekkür ederiz.

\section{Kaynaklar}

1. Öztek, Z. Halk sağlığı sözlüğü. T.C Sağlık Bakanlığı Sağlık Projesi Genel Koordinatörlüğü, Ankara, 1998.

2. WHO. Health systems performance assessment debates, methods and empiricism. Editors: Murray, CJL, Evans, DB. World Health Organization, Geneva, 2003.

3. Reidpath DD, Allotey P. Infant mortality rate as an indicator of population health. J Epidemiol Community Health 2003; 57: 344-6. Abstract / Full Text) / (PDDF

4. Akdağ R. İlerleme raporu Türkiye sağlıkta dönüšüm programı. Ankara: T.C. Sağlık Bakanlığı Yayını, Yayın no: 749, 2008: 26.

5. TNSA 2008. Türkiye nüfus ve sağlık araștırması 2008 ön raporu. Hacettepe Üniversitesi Nüfus Etütleri Enstitüsü, T.C Sağlık Bakanlığı Ana Çocuk Sağlığı ve Aile Planlaması Genel Müdürlüğü, T.C Başbakanlık Devlet Planlama Teşkilatı Müsteșarlığı. Türkiye Bilimsel ve Teknolojik Araştırma Kurumu (TÜBITAK) "Kamu kurumları araştırma ve geliştirme projelerini destekleme programı”. Ankara, Mart 2009.

6. Bursa İI Sağlık Müdürlüğü web sayfası. http://bsm.gov.tr/istatistik/hayati.asp (Erişim tarihi: 09.07.2009). 7. Bursa II Sağlık Müdürlüğü web sayfası. http://www.bsm.gov.tr/ duyuru/duyuru.asp?no=1049 (Erișim tarihi: 08.10.2009). 8. Hill AB. Principles of Medical Statistics. 7. ed. London: The Lancet Limited, 1961: 310

9. Bursa Valiliği il Sağlık Müdürlüğü'nün 16.09.2009 tarih ve B.104.ISM.04.16.00.12/52 sayılı yazısı.

10. Bursa Valiliği III Nüfus ve Vatandașlık Müdürlüğü’nün 26.11.2009 tarih ve B.05.0.NÜV.4.16.00.00/120/25063 sayılı yazısı.

11. Özcan C, Mortan K. 1989 yılı için Türkiye'de bebek ölüm hızını belirleme araştırması. TCDD Hastaneleri Tıp Bülteni 1992; 1: 13-20.

12. T.C Sağlık Bakanlığı Ana Çocuk Sağlığı ve Aile Planlaması Genel Müdürlüğü’nün B.10.0AÇS.0.12.00.14/610-3738 sayılı yazısı.

13. Günay T, Kılıç B, Şemin S, Pabucçuoğlu O. Narlıdere Eğitim Araştırma ve Sağlık Bölgesi'nde 1999 yılı kayıt dışı bebek ölümleri. Sağlık ve Toplum 2002; 12: 52-5.

14. Genel nüfus sayımı 2000. Nüfusun sosyal ve ekonomik nitelikleri. Bursa. T.C Başbakanlık Devlet İstatistik Enstitüsü, Ankara, 2002:79.

15. Bulut A, Gökçay G, Neyzi O, Shorter F. İstanbul'da bebek ve çocuk ölümleri. Nüfusbilim Dergisi 1990; 12: 5-18. 